contraer GPAA entre los "fumadores actuales" $(\mathrm{RP}=1,37$; IC95\%: 1,00 a 1,87; $P=0,050)$ que entre personas que nunca fumaron. En cambio, el resumen de los efectos fijos del segundo modelo indicó que los "ex fumadores" no corrían un riesgo mayor de contraer GPAA que los "no fumadores" (RP = 1,03; IC95\%: 0,77 a 1,38; $P=0,85$ ).

Este es el primer metaanálisis en el que se evalúa si el consumo de cigarrillos constituye un factor de riesgo de GPAA. Según estos resultados, los fumadores de cigarrillos están en mayor riesgo de padecer esta enfermedad que las personas que nunca han fumado. A diferencia de otros factores de riesgo conocidos, el hábito de fumar es un factor modificable, por lo que en las campañas contra el tabaquismo debe hacerse hincapié en el posible riesgo de contraer GPAA. (Bonovas S, Filioussi K, Tsantes A, Peponis V. Epidemiological association between cigarette smoking and primary open-angle glaucoma: a meta-analysis. Public Health. 2004;118: 256-261.)

\section{Características de la infección invasora por Haemophilus influenzae tipo b en Paraguay}

Hasta 1997, Haemophilus influenzae tipo b (Hib) era la causa de 25 a 50\% de los casos anuales de meningitis bacteriana aguda (MBA) en América Latina, con una tasa de mortalidad de $40 \%$. Esta situación epidemiológica ha venido cambiando en los últimos años gracias a la incorporación de la vacuna contra Hib en los programas de vacunación pública de la mayoría de los países latinoamericanos. Sin embargo, en los países de menos recursos, donde el uso de esta vacuna no se ha generalizado, la infección causada por esta bacteria - en primer lugar la meningitis bacteriana- aún constituye la causa principal de morbilidad y mortalidad en lactantes y niños. Además, esta bacteria causa otros trastornos y enfermedades, como septicemia, artritis, epiglotitis, celulitis y neumonía, y ha adquirido resistencia a varios antibióticos, especialmente en los países en desarrollo.

El objetivo de este estudio fue documentar las características clínicas y epidemiológicas de la enfermedad invasora causada por Hib en niños de Paraguay.

Se realizó un análisis retrospectivo de todos los pacientes menores de 15 años de edad con un diagnóstico de infección invasora por Hib, según criterios clínicos y de laboratorio, que fueron atendidos en el Instituto de Medicina Tropical (IMT) de Asunción, Paraguay, entre enero de 1991 y septiembre de 1995.

Se anotaron los datos demográficos, clínicos y microbiológicos de los casos que cumplieron con los criterios de inclusión. Los pacientes se presentaron con un diagnóstico clínico de meningitis, epiglotitis, neumonía, pericarditis, bacteriemia oculta, celulitis, artritis séptica u osteomielitis. La infección se confirmó por métodos bacteriológicos, mediante el aislamiento de Hib en la sangre, en el líquido cefalorraquídeo (LCR) o en otro líquido o tejido estéril (derrame pleural, sinovial o pericárdico, muestras de tejido óseo, de piel, o de tejidos blandos) o mediante la detección de antígenos contra Hib en el LCR (solamente en casos de meningitis).

Los pacientes se clasificaron de acuerdo con el tipo de infección inicial, meníngea o extrameníngea. En el grupo de pacientes con meningitis, se consideraron complicaciones los trastornos cardíacos o cerebrovasculares repentinos, los abscesos cerebrales y el derrame subdural. Las secuelas en el momento del alta hospitalaria fueron hidrocefalia, afectación de los nervios craneales, pérdida auditiva y retraso psicomotor o mental (definido como un retraso del desarrollo de 6 meses o más). La deficiencia auditiva se definió como ligera si el umbral auditivo era de 30 a $40 \mathrm{~dB}$, moderada si estaba entre 50 y $70 \mathrm{~dB}$ y grave cuando era mayor de $70 \mathrm{~dB}$.

En el período estudiado se atendió en el IMT a 102 pacientes pediátricos (58 niños y 44 niñas) con infección invasora por Hib. Se atendieron de 19 a 29 casos anuales, con excepción del año 1994, en el que solo se atendió a 10 pacientes. Durante los 5 años estudiados, las tasas anuales de infección invasora, meningitis e infección extrameníngea en niños menores de 5 años de edad del área de la Gran Asunción fueron de 21,6, 17,7 y 3,9 por 100 000, respectivamente. En todos los años, menos 1994, se observó poca variación en el número de casos registrados anualmente.

La edad media de los pacientes fue de 15,3 \pm 12 meses (entre 1 mes y 14 años). De ellos, 50\% eran menores de 1 año de edad y $80 \%$ menores de 2 años. Solo 3 casos (3\%) se encontraban en el grupo de edad de 5 a 14 años. En general, 36\% de los pacientes (37/102) tenían desnutrición y 32\% (12/37), desnutrición grave. Ningún paciente estaba vacunado contra Hib. De los 102 pacientes, 83 (81\%) tenían MBA y 19 (19\%), infección extrameníngea. Ambos grupos se analizaron por separado.

La infección meníngea se diagnosticó en los 83 pacientes mediante el aislamiento microbiológico o la detección de antígenos de Hib en el LCR. En 71 de estos casos (85\%), el sistema nervioso central fue el sitio de la infección. Doce niños $(14 \%)$ tuvieron otras infecciones: neumonía (10 casos), osteomielitis con artritis adyacente (un caso) y celulitis (un caso). La edad media de los pacientes con meningitis fue de 15,3 \pm 14,3 meses; 46 (55\%) de ellos eran niños y $37(45 \%)$ eran niñas. El grupo de edad más afectado por la MBA fue el de menores de 1 año (45 pacien- 
tes, $54 \%$ ). Veinte pacientes (24\%) tenían menos de 6 meses de edad.

De los casos con meningitis, 26 pacientes (31\%) presentaron desnutrición, que fue grave en dos de los casos. El tiempo transcurrido entre la aparición de los síntomas y el diagnóstico de meningitis fue de 1 a 7 días (mediana $=4,9 \pm 3,9$ días). La mediana del tiempo transcurrido entre la aparición de los síntomas y el ingreso al hospital fue de 5,7 $\pm 4,3$ días en los niños de 1 a 11 meses de edad y de 5,6 3,7 días en los niños de 12 a 23 meses; en cambio, este período fue de 3,9 $\pm 2,9$ días en los niños de 24 a 60 meses de edad. No obstante, estas diferencias no fueron estadísticamente significativas. Antes de las 24 horas recibieron tratamiento con antibióticos 28 pacientes $(34 \%)$. Se encontró resistencia a la ampicilina en 30\% de las cepas aisladas de Hib; $20 \%$ de las cepas mostraron resistencia al cloranfenicol y $10 \%$ a ambos antibióticos.

Las manifestaciones clínicas más frecuentes fueron la fiebre $(89 \%)$, los vómitos (58\%), los trastornos cardíacos y cerebrovasculares repentinos (54\%) y las afecciones sensoriales de origen central (54\%). Estas manifestaciones fueron similares en todos los grupos de edad.

La mortalidad general por meningitis fue de $13 \%$ y disminuyó a medida que aumentaba la edad: de $22 \%(10 / 45)$ en pacientes menores de 12 meses de edad a $2,6 \%(1 / 38)$ en niños mayores $(P<0,02)$. No se encontraron diferencias significativas en el tiempo transcurrido entre la aparición de los síntomas y el inicio del tratamiento entre los niños que murieron $(6,5 \pm 4,6$ días) y los niños que sobrevivieron $(4,6 \pm 1,9 ; P>0,1)$.

La concentración de glucosa en el LCF en el momento de la consulta al hospital fue el mejor factor pronóstico de mortalidad. De los pacientes fallecidos, $91 \%$ presentaban concentraciones de glucosa en el LCF menores de $10 \mathrm{mg} / \mathrm{dL}$ en el momento del ingreso al hospital, mientras que solo $61 \%$ de los pacientes que sobrevivieron (44/72) presentaban concentraciones de glucosa de $10 \mathrm{mg} / \mathrm{dL}$ o menos $(P<0,05)$.

Se observaron secuelas graves en 39\% de los pacientes sobrevivientes (28/72). Los sobrevivientes menores de 24 meses de edad presentaron una o varias de las siguientes secuelas: pérdida auditiva, hidrocefalia moderada o grave y retraso mental moderado o grave. Las secuelas a largo plazo fueron más frecuentes en los niños menores de 12 meses (51\%) seguidos de los de 24 a 60 meses de edad (42\%).

La infección extrameníngea por Hib se observó en $19 \%$ de los pacientes (19/102), de los cuales $79 \%$ (15/19) tenían neumonía. De estos casos, 87\% (13/15) tenían derrame pleural. Se logró aislar Hib de la sangre de 9 pacientes; del líquido pleural de 13 , y de ambos en 6 casos. La distribución por eda- des fue similar a la observada en los casos de meningitis (73\% eran niños menores de 24 meses y $27 \%$ tenían entre 24 y 60 meses de edad). En $20 \%$ de los casos de neumonía por Hib se encontraron trastornos del sistema nervioso central, lo cual indica la utilidad de realizar una punción lumbar en todos los casos de infección invasora por Hib.

Los resultados del presente trabajo indican que, a diferencia de lo encontrado en otros lugares, la infección por Hib en Paraguay afecta principalmente a los niños durante el primer año de la vida (50\% de los casos) y especialmente durante los primeros 6 meses (24\% de todos los casos notificados). Esto significa que el esquema de vacunación recomendado por la Academia Estadounidense de Pediatría (a los 2, 4 y 6 meses de edad, con una dosis de refuerzo a los 12-15 meses) podría ser inapropiado para el Paraguay. Se deben evaluar otras opciones, como la inmunización materna, o establecer esquemas de vacunación a edades más tempranas, por ejemplo, a los 4, 8-12 y 16 semanas, con una dosis de refuerzo a los 12-15 meses. (Basualdo W, Arbo A. Invasive Haemophilus influenzae type b infections in children in Paraguay. Arch Med Res. 2004;35:126-133.)

\section{Validación cultural de instrumentos para el diagnóstico de la demencia en países en desarrollo}

Independientemente de los criterios que se observen para diagnosticar la demencia, el diagnóstico se debe basar en tres parámetros: el deterioro de al menos dos dominios de la función cognoscitiva, incluida la memoria; la afectación del funcionamiento social u ocupacional del paciente; y la ausencia de otro diagnóstico que explique los síntomas, como el de depresión.

Según el método estándar para el diagnóstico de la demencia en dos etapas, los instrumentos de tamizaje cognoscitivo pueden identificar a la mayoría de las personas que no padecen de demencia. Sin embargo, en los países en desarrollo, la baja escolaridad, el analfabetismo y la falta de familiaridad con la aritmética en amplios sectores de la población pueden llevar al diagnóstico erróneo de demencia en personas que tienen limitaciones cognoscitivas. Para superar esa dificultad es necesario adaptar los instrumentos de tamizaje a poblaciones de bajo nivel cultural y educacional, de manera que no sea un requisito que la persona evaluada sepa leer, escribir o realizar operaciones aritméticas.

Este trabajo describe los resultados obtenidos durante un estudio piloto multicéntrico multinacional en el que se evaluaron los resultados de la aplicación de instrumentos para el diagnóstico de la demencia, adaptados para su uso con personas de bajo 